\title{
Gender Analysis of Students' Creativity (Case Study: Faculty of Agriculture/University of Zanjan)
}

\author{
Zahra Hooshmandan Moghaddam Fard and Ali Shams \\ Agricultural Extension and Education, Faculty of Agriculture, University of Zanjan, Iran \\ Department of Agricultural Extension, Communication and Rural Development, Faculty of Agriculture, \\ University of Zanjan, Iran
}

\begin{abstract}
Any planning with the objective of increasing creativity should consider the gender differences. The purpose of this correlational- descriptive study was to investigate the correlation between students' creativity and their gender. The research tool was a questionnaire which consists some demographic and educational variables and Torrance standard test of creativity. By conducting a pilot test and calculating alpha Cronbach equals with 0.9, its reliability was confirmed. The statistical population consists all BSc. Students in the faculty of agriculture, University of Zanjan ( $N=724)$ which 217 students (64 male and 153 female) as a sample were identified through using of Cochran formula under stratified randomized sampling method. Majority of female students (82.4 percent) and male students (79.7 percent) had average and lower than average of creativity in total. Chi-Square test revealed that there is no meaningful correlation between creativity and its four dimensions (fluency, flexibility, Originality, and elaborations) with gender.
\end{abstract}

Keywords: Agriculture Students, Creativity, Correlation, Gender Analysis

\section{Introduction}

In recent years, the unemployment rate of university college graduates and agricultural graduates has increased in particular, and it is imperative that agricultural faculties pay special attention to improving the entrepreneurial skills of students. Entrepreneurship is a process or concept in which an entrepreneur engages with new ideas to identify new opportunities and utilize various resources to create new businesses, companies, and new and innovative growth organizations [1]. In recent studies, creativity has attracted a lot of attention as one of the most influential human capital on entrepreneurship [2]. Investigating the status quo of the creativity of individuals and their associated factors is essential for any future planning. [2]- [3]. The history of gender studies in the literature of creativity dates back to 1976 and the study of Kogan (1974). He believed that if a behavioral scientist claims that a genus of another is more creative, he will encounter a mass of critics, and adds the caution that there is a relative equality between men and women in terms of creativity. [4].

In 2008, Baer and Kaufman, by conducting a meta-analysis study, reported that, despite some differences, there is a relative equality in the ability of creativity between men and women. It seems that no study is decisively spoken about the gender analysis of creativity, and more studies are needed in this area. [5]. Studies in the fields of student creativity show that there was a significant difference between male and female students' creativity in some academic disciplines, but in some fields this difference was not significant. In recent years, the trend of admission of female students in agricultural fields has increased, and at the University of Zanjan, Faculty of Agriculture, about two-thirds of all students are female. Given the nature of the field of agriculture and its relevance to practical work, the current trend of admission of female students is the consideration of some policymakers and planners. Researching this subject scientifically and from different angles can provide applied results for future planning because due to high unemployment of agricultural graduates, a study of related factors with students' creativity as an important component of their entrepreneurship should be emphasized.

\section{Methodology}


The present study is a descriptive correlational study in terms of data collection. In terms of its purpose, it is considered as an applied research and in terms of controlling of its variables, it is a field study. The research instrument was a questionnaire with consisting of two parts of students 'educational characteristic and student creativity measurements. To measure creativity, the Torrance Creativity Standard Questionnaire was used. The questionnaire consists of 60 three-choice questions which are set in four sections: Fluency, Flexibility, Originality, and Elaboration, each of which has 15 questions. Considering the multiple uses of Torrance 's Creativity Questionnaire (1979) [6], in previous studies, its validity has been confirmed. By performing a preliminary study and calculating the Cronbach's alpha coefficient, it was 90\%. The statistical population consisted of all students of agricultural majors in the University of Zanjan, Iran (724 students) which identified 217 students as a sample size by using Cochran sampling formula and selected by stratified random sampling method. The collected data were analyzed by SPSS21. The descriptive statistics (mean and standard deviation) and inferential statistics (correlation coefficient and mean comparison tests) were used to analyze the data.es.

\section{Result and Discussion}

The mean age of the students was 22.5 years with a standard deviation of 1.56 years. The majority of students $(70.5 \%)$ were girls and the rest (29.5\%) were boys. Most students (79.7\%) were urban and $20.3 \%$ were rural. On average, students completed 82 units. Also, most of them (96.3\%) lacked any kind of work experience. The average student's academic achievement score was 15.8. In terms of interest in the field of study, the interest of more than half of the students (51.9\%) was moderate to low and $23.1 \%$ high and $25 \%$ was very high. As explained in the research methodology, the creativity variable was measured in the form of a composite index consisting of 60 questions. These questions were classified into four dimensions of creativity including, Fluency (questions 1-15), flexibility (questions 16-30), Originality (questions 31-45) and Elaboration (questions 36-60) with three choice option.

Based on the results, it was found that most students (45.2\%) in terms of fluency are in a very low status. In terms of flexibility, most students (41.5\%) are at a high level of flexibility. In the dimension of the originality, most students $(64.1 \%)$ are low, and finally, most students $(47 \%)$ are at high levels in terms of elaboration. The results of the chi-square test showed that in all four dimensions of creativity, there was no difference between girls and boys, in other words, the four dimensions of creativity were not related to gender. As shown in Table 1 , most female students $(82.4 \%)$ were modest and less creative in terms of creativity, and in the case of male students, the majority of them (79.7\%) had moderate and low levels of creativity. There are no significant differences between girls' creativity with boys and there is no significant relationship between gender and creativity among students.

TABLE I

Frequency Distribution Of Students In Terms Of Their Creativity Level And Their Gender

\begin{tabular}{|c|c|c|c|c|c|c|c|c|c|}
\hline \multirow{2}{*}{$\begin{array}{l}\text { Creativity } \\
\text { level }\end{array}$} & \multicolumn{3}{|c|}{ Total } & \multicolumn{3}{|c|}{ Girls } & \multicolumn{3}{|c|}{ Boys } \\
\hline & Frequency & $\begin{array}{c}\text { Valid } \\
\text { percent }\end{array}$ & $\begin{array}{c}\text { Cumulative } \\
\text { percent }\end{array}$ & Frequency & $\begin{array}{c}\text { Valid } \\
\text { percent }\end{array}$ & $\begin{array}{c}\text { Cumulative } \\
\text { percent }\end{array}$ & Frequency & $\begin{array}{l}\text { Valid } \\
\text { percent }\end{array}$ & $\begin{array}{c}\text { Cumulative } \\
\text { percent }\end{array}$ \\
\hline Very Low & 13 & 6 & 6 & 11 & 7.2 & 7.2 & 2 & 3.1 & 3.1 \\
\hline Low & 61 & 28.1 & 34.1 & 41 & 26.8 & 34 & 20 & 31.3 & 34.4 \\
\hline Mediate & 103 & 47.5 & 81.6 & 74 & 48.4 & 82.4 & 29 & 45.3 & 79.7 \\
\hline High & 23 & 10.6 & 92.2 & 18 & 11.8 & 94.1 & 5 & 7.8 & 87.5 \\
\hline Very High & 17 & 7.8 & 100 & 9 & 5.9 & 100 & 8 & 12.5 & 100 \\
\hline
\end{tabular}

$\mathrm{Sig}=0.304 \quad \mathrm{X} 2=4.84$

The results of this study showed that in both groups of male and female students, creativity is moderate and less than average, which was consistent with the findings of Zahabion and Ahmadi (2009) [7], but contrary to the findings of Mashizabadi et al. (2014) [8].The results of the Chi-square test showed that there was no significant difference between male and female students in overall creativity and all four dimensions, and there was no significant relationship between gender and creativity. In the past study in this field, such as Zahabion and Ahmadi (2009) [7], Mardanshahi (2014) [9], Jamalzadeh and Vares (2014) [10], and Olatoye et al. (2010) 
[11], Similar results were reported. Given the low level of creativity of students and the fact that creativity does not correlate with gender, it can be concluded that any planning in this field can be done concurrently for both groups. Therefore, it is necessary for agricultural colleges to enhance the creativity of students, and in particular the two dimensions of low levels named as originality and Fluency. To do this, it is suggested that by reviewing educational programs and designing courses related to the needs of students, providing adequate opportunities for the development of creativity and the presentation of new ideas, creating Innovative conditions for independent and spontaneous learning could provide a good environment for speeding up the development of students' creativity. To do this, it is possible to engage creative activities in each course unit and take special incentives for new and innovative ideas in a variety of ways, such as holding workshops of creative thinking and increasing the spirit of criticism. Of course, the results of the present study were consistent with the findings of Ganji et al. (2015) [12], on the meaningful relationship between creativity and gender.

\section{References}

[1] M. Musavi, "Studying the Barriers to Entrepreneurship Development; (Case Study: Payam Noor University of Khorasan Razavi)," Human Sciences Journal of Payam Noor, 2014, vol. 4, pp.35-45.

[2] H. Shakiba, "Source of creativity in education," publication of Ministry of Education. First Edition. Tehran. 2014

[3] S. Da Costa, D. Páez, F. Sánchez, M. Garaigordobil, and S. Gondim, "Personal factors of creativity: A second order meta-analysis," Journal of Work and Organizational Psychology, 2015, vol. 31, no. 3, pp.165-173.

https://doi.org/10.1016/j.rpto.2015.06.002

[4] N. Kogan, "Creativity and sex differences. Journal of Creative Behavior," 1974, vol. 8, pp. 1-14. https://doi.org/10.1002/j.2162-6057.1974.tb01103.x

[5] J. Baer and J. C. Kaufman "Gender differences in creativity," Journal of Creative Behavior, 2008, vol.42, no. 2, pp.75105. https://doi.org/10.1002/j.2162-6057.2008.tb01289.x

[6] E. P. Torrance "The search for satori and creativity," Buffalo, NY: Bearly Limited. 1979

[7] L. Zahabion, and GH. Ahmadi, "Creative thinking and its relationship with academic success in Islamic Azad University: students of Khorasgan Branch,” Research in Curriculum Planning, 2009, vol. 21. No.1, pp.61-78.

[8] Z. Mashizabadi, N. Seyyed Fatemi, L. Berimnejad, H. Haqqani and M. Yazdani Zenuz "Comparison of creativity skills in first to fourth year undergraduate students," Iranian Journal of Nursing Research. 2014, vol.8, no. 28, pp.49-57.

[9] M.M. Mardanshahi "Investigating the level of creativity and risk aversion of BSc. Students of Agricultural Sciences and Natural Resources in Sari University," Quarterly journal of creativity and initiatives in human science, 2014, vol.3, no. 3, pp.1-21.

[10] M. Jamalzadeh and M. Vares "The Relationship Between Dimensions of Targeting Orientation and Creativity in Islamic Azad University Students of Shiraz Branch,” Quarterly of Leadership and Educational Management, 2014, vol. 7, no.2, pp. 45-58

[11] R. A. Olatoye, S. O. Akintunde, and M. I. Yakasai,"Emotional intelligence, creativity and academic achievement of business administration students," Electronic Journal of Research in Educational Psychology, 2010, vol.8, no.2, pp.763786.

[12] K. Ganji, S. Taghavi, and F. Azimi, "The meta-analysis of variables associated with creativity. Innovation and Creativity in Human Science, 2015, vol. 4, no. 4, pp. 1-49 